\title{
Community ECHO (Extension for Community Healthcare Outcomes) Project Promotes Cross-Sector Collaboration and Evidence-Based Trauma-Informed Care
}

\author{
Christina A. Buysse ${ }^{1}$ (1) $\cdot$ Barbara Bentley $^{2} \cdot$ Linda G. Baer $^{1} \cdot$ Heidi M. Feldman ${ }^{1}$ \\ Accepted: 24 November 2021 / Published online: 11 January 2022 \\ (c) The Author(s), under exclusive licence to Springer Science+Business Media, LLC, part of Springer Nature 2021
}

\begin{abstract}
Introduction Adverse Childhood Experiences (ACEs) are traumatic events that occur before 18 years. ACEs, associated with increased health-risk behaviors and chronic health disorders, disproportionately impact people from marginalized communities. Evidence shows that toxic stress from ACEs and adverse social determinants of health can be prevented and treated with trauma-informed care (TIC). The purpose of this educational program was to train a maternal and child health workforce to bring evidence-based trauma-informed care to all impacted people.

Methods Participants were professionals recruited from Federally Qualified Health Centers, community behavioral health organizations, educational institutions, and agencies serving low-income children and families. 100 unique participants representing 3 counties and 54 agencies joined sessions. Twelve virtual educational sessions were convened over 6 months using the Project ECHO® model via Zoom technology. Sessions consisted of didactic lectures and case-based discussions. Results After completion of the series, participants reported high satisfaction and increased knowledge and confidence in using TIC best practice skills. After participation, a significant number of participants voluntarily completed an additional online training about the specific TIC best practices that had been taught in the ECHO. Participants rated the opportunity for interprofessional collaboration and peer support for vicarious trauma as program strengths.

Discussion This project demonstrated feasibility and effectiveness in delivery of a curriculum on trauma-informed care to cross-sector, multi-agency maternal and child health workforce professionals using the Project ECHO® model. Robust interprofessional collaboration and participants' request for more sessions demonstrate the potential for this model to effect change at a local systems level.
\end{abstract}

Keywords Adverse Childhood Experiences (ACEs) · Project ECHO® . Trauma-informed care $\cdot$ Maternal and child health Workforce development

\section{Significance}

What is already known Adverse Childhood Experiences (ACEs) are associated with unfavorable mental and physical health outcomes. Trauma-informed care (TIC) leads to human and economic cost savings, but the maternal and child health $(\mathrm{MCH})$ workforce lacks adequate definitions

Christina A. Buysse

tbuysse@stanford.edu

1 Department of Pediatrics, Stanford University School of Medicine, Stanford, CA 94305, USA

2 Lucile Packard Children's Hospital Stanford, Palo Alto, CA 94304, USA of and training in TIC best practices. The Project ECHO ${ }^{\circledR}$ (Extension for Community Healthcare Outcomes) model is known to effectively increase participant skills.

What this project adds Twelve virtual Project $\mathrm{ECHO}{ }^{\circledR}$ educational sessions delivered to $\mathrm{MCH}$ professionals from different sectors and agencies was associated with high participant satisfaction and increased self-reported participant knowledge and confidence in using evidence-based TIC best practices. 


\section{Introduction}

Adverse Childhood Experiences (ACEs) are stressful events that occur in childhood. When first described in the Centers for Disease Control and Prevention (CDC) and Kaiser Permanente Adverse Childhood Experiences Study in 1998, 10 specific ACEs were described: physical, emotional, and sexual abuse; physical and emotional neglect; household challenges caused by a household member who experienced mental illness, used substances, experienced intimate partner violence, was absent due to divorce or separation, or was incarcerated (Centers for Disease Control \& Prevention, 2019a; Felitti et al., 1998). Exposure to ACEs has been associated with poor health outcomes, increased behavior risks, and decreased educational and economic outcomes. Adults who have experienced 4 or more ACEs have 1.5 times incidence of cardiac disease, 5 times risk of depression, and 10 times risk of substancedependence than a person with no ACEs (Bhusan et al., 2020). Children exposed to ACEs have increased behavioral, learning, and attentional difficulties (Jones et al., 2020). People in marginalized communities are more likely to experience elevated ACEs. Social determinants of health $(\mathrm{SDoH})$, such as poverty, systemic racial injustice, and discrimination, exacerbate the negative impact of ACEs on health. Sixty percent of US adults report $\geq 1$ lifetime ACE and $15.6 \%$ report $\geq 4$ ACEs (Merrick et al., 2018). ACEs cost an estimated $\$ 748$ billion annually in North America in direct healthcare costs and disabilityadjusted life-years (Bellis et al., 2019).

Trauma-informed care (TIC) describes efforts to prevent and respond to traumatic events, including ACEs. The definition of TIC has been historically inconsistent, fragmented and non-standardized across systems of care (Bargeman et al., 2020). Routine screening for ACEs has been controversial because the next steps to take when individuals have been exposed have been unclear (Allen $\&$ Abresch, 2018). Originally viewed from the perspective of life course theory ( $\mathrm{Lu}, 2014)$, the conceptualization of TIC has evolved to also include guidance for direct clinical response. Recent discussions of TIC embrace the upstream systems changes known to promote health equity, while simultaneously acknowledging the need for direct intervention when stressed individuals and families are identified (Forkey et al., 2021).

This paper evaluates an ACEs training program designed to increase knowledge and skills of a diverse sample of community-based primary care clinicians (PCCs), professionals from maternal and child health $(\mathrm{MCH})$, and representatives of community agencies who serve children and families with public health insurance. To ground the training in a conceptual framework, we used the TIC definition of the California Office of the Surgeon General and the Department of Healthcare Services ACEs Aware Initiative: "care that includes awareness of the prevalence of trauma and adversity (including early adversity) and understanding of the impacts of trauma on physical, emotional, and mental health. Its principles help support a strengths-based and nonjudgmental approach to toxic stress risk assessment and intervention, and to prevent inadvertent re-traumatization of patients and vicarious traumatization of service providers." We adapted the primary, secondary, and tertiary prevention best-practice strategies for TIC from the ACEs Aware Initiative (Bhusan et al., 2020). The CDC recommends implementing programs in the community and schools to prevent violence, treat stress, and provide social and economic supports (Centers for Disease Control \& Prevention, 2019b). The ACEs Aware Initiative builds upon a population-based approach by adding specific evidence-based best practice recommendations for screening and responding to ACEs in direct patient care.

Barriers to implementation of TIC have been identified across care sectors. Patient privacy laws and silos of care inhibit interprofessional communication and referrals between $\mathrm{MCH}$ care providers. Medical education training programs have not prepared PCCs to deliver TIC and manage complex behavioral health problems in their clinics (Dichter et al., 2018; Horowitz \& Cousins, 2006; Horwitz et al., 2015). Behavioral Health providers report a similar lack of time and training as barriers to providing TIC (Sharif et al., 2021).

Continuing education workshops increase capacity of community providers to provide responsive TIC (Palfrey et al., 2019). PCCs who receive continuing medical education (CME) have been found to screen more frequently for behavioral health issues than those who have not received training (Green et al., 2019). Providing professional development activities about TIC strategies to educators in nursing and criminal justice led to significant increases in treatment knowledge and self-perceived ability to support students impacted by trauma (Doughty, 2020). Child welfare workers reported increased skills in identification and linkage to services after TIC trainings (Kerns et al., 2016). The Johnson City Tennessee System of Care has been bringing participants across sectors of education, law enforcement, judicial, and behavioral health to bimonthly meetings about TIC since 2016. These meetings have raised familiarity with and created systems of TIC amongst participants. Challenges to this work include the logistics of scheduling and preparing for meetings and communication within the participant group (Clements et al., 2020).

Project ECHO ${ }^{\circledR}$ (Extension for Community Healthcare Outcomes) is a model that simplifies coordination of training meetings between geographically and organizationally 
discrete participants. The Project ECHO® teleconsultation model effectively promotes best practice care among participants (Arora et al., 2011; Hostutler et al., 2020). Project ECHO ${ }^{\circledR}$ dramatically improves both capacity and access to specialty care for rural and underserved populations (Nakamura et al., 2019). As participants gain independence and their skills and self-efficacy grow in a community ECHO program, participant career satisfaction has been shown to improve (Arora et al., 2017). To our knowledge, the efficacy of using a Project $\mathrm{ECHO} \circledast$ series to educate a diverse $\mathrm{MCH}$ workforce about ACEs and TIC with participants from a wide range of care sectors has not been evaluated.

\section{Methods}

\section{Participants}

Participants were recruited from a known network of interprofessional $\mathrm{MCH}$ colleagues in three local counties. To encourage participation, formal procedures were followed to establish CME and CE credit for participants. All research was conducted in accord with prevailing ethical principles. This project did not meet the definition of human subjects research by the Stanford Institutional Review Board because they determined it an educational program, and therefore consent for participation and surveys was not required.

\section{Procedures}

Our team, consisting of pediatric developmental and behavioral pediatric clinicians and adult education specialists, utilized the Project ECHO® model to deliver 12 virtual case-based interactive sessions about TIC to a diverse $\mathrm{MCH}$ workforce from multiple care sectors and organizations in 3 California counties. Using distance learning teleconferencing, the all-teach, all-learn community learned through discussion of de-identified cases presented by participants. A website was developed as a communication hub for the group (https://med.stanford.edu/aces.html).

The ECHO series was convened for 12 bimonthly sessions over 6 months during the COVID-19 pandemic. Almost all participants joined from their own homes. Each 75-min session consisted of a 15-min didactic session, a 55-min case-based discussion, and a wrap-up. The curriculum for the series was informed by the ACEs Aware Initiative trainings. See Table 1 for curriculum. Leaders facilitated the group discussion and elicited systemic barriers to TIC. A common language for TIC was used for all presentations and communications, and participants were encouraged to consider solutions from both individual and systems levels. The last two sessions brought the participants into small break-out groups by sector and county to discuss specific barriers and potential solutions within their communities.

\section{Measures}

Participant surveys were collected at enrollment (Baseline Survey), after each session (Post-Session Surveys), and at the conclusion of the series (Final Survey). Participants completed Baseline Surveys generated by email, including demographic information. Post-session surveys were completed after each session. Each survey included questions about overall quality of the session. A voluntary Final Survey was completed electronically by a self-selected subset of the participants and requested self-reported attainment of each session's key learning objective using a 5-point Likert scale.

All surveys were delivered electronically using Qualtrics. Data from the Baseline Survey, Post-Session Surveys and Final survey were exported into the IBM ${ }^{\circledR}$ SPSS ${ }^{\circledR}$ Version 26 software platform for analysis.

\section{Data Analysis}

We analyzed results using chi-square for comparing wholegroup proportions of dichotomous variables from Baseline to Final Surveys, and McNemar's test and paired-sample $t$ tests (for dichotomous and continuous variables respectively) to measure changes within paired Baseline and Final groups.

\section{Results}

\section{Participation}

A total of 100 unique participants attended the sessions. Participants represented 54 organizations across 3 counties. The average number of participants per session was $44(\mathrm{M}=44.2, \mathrm{SD}=8.41$, range: $31-54)$. Participants each attended an average of 5 sessions out of the 12 offered $(\mathrm{M}=5.12, \mathrm{SD}=3.74$, range: $1-12)$. The participants were diverse in terms of roles and organizations, and included PCCs, behavioral health providers, $\mathrm{MCH}$ nurses, child welfare workers, educators, community health workers representing various family resource and support organizations, and an attorney from a medical-legal partnership. Table 2 describes participants and organizations by county.

\section{Evaluation}

After the sessions, participants reported increased knowledge about ACEs and evidence-based TIC. Post-Session Survey responses indicated high levels of satisfaction with 


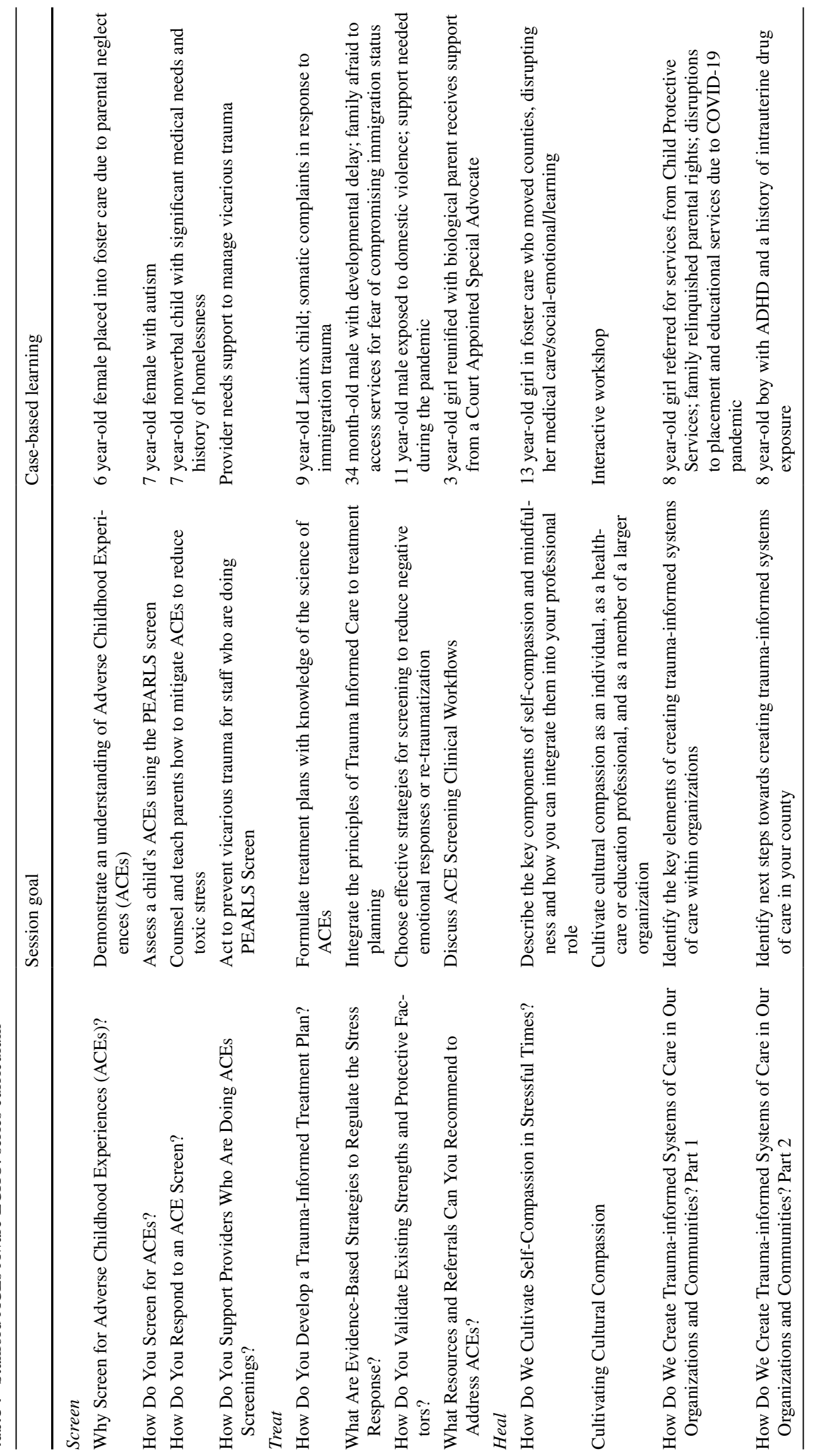


Table 2 Participants enrolled in Stanford ACEs Aware ECHO by care sector

\begin{tabular}{|c|c|c|c|}
\hline \multirow[t]{2}{*}{ Care sector } & \multicolumn{3}{|l|}{ County } \\
\hline & $\begin{array}{l}\text { County } 1 \text { individuals (repre- } \\
\text { sented organizations) }\end{array}$ & $\begin{array}{l}\text { County } 2 \text { individuals (repre- } \\
\text { sented organizations) }\end{array}$ & $\begin{array}{l}\text { County } 3 \text { individuals } \\
\text { (represented organiza- } \\
\text { tions) }\end{array}$ \\
\hline $\begin{array}{l}\text { Healthcare provider (e.g. MD, DO, NP, MSN, } \\
\text { CNS, RN) } \\
(\mathrm{n}=46)\end{array}$ & $9(7)$ & $20(6)$ & $17(8)$ \\
\hline $\begin{array}{l}\text { Behavioral health } \\
\text { (e.g. LCSW, PhD, PsyD, MFT) }(n=31)\end{array}$ & $6(4)$ & $8(7)$ & $17(7)$ \\
\hline $\begin{array}{l}\text { Education } \\
(\mathrm{n}=12)\end{array}$ & $2(2)$ & $8(3)$ & $2(1)$ \\
\hline $\begin{array}{l}\text { Early intervention } \\
(\mathrm{n}=3)\end{array}$ & $2(1)$ & $1(1)$ & --- \\
\hline $\begin{array}{l}\text { First } 5 \\
(\mathrm{n}=3)\end{array}$ & $2(1)$ & --- & $1(1)$ \\
\hline $\begin{array}{l}\text { Family support agency } \\
(\mathrm{n}=4)\end{array}$ & $2(2)$ & $1(1)$ & $1(1)$ \\
\hline Legal/justice & $1(1)$ & --- & --- \\
\hline$(\mathrm{n}=1)$ & $\mathrm{n}=24(18)$ & $\mathrm{n}=34$ & $\mathrm{n}=34$ \\
\hline
\end{tabular}

Total participants $=100$

Total organizations $=54$

Table 3 Mean participant-rated score on twelve post-session surveys ${ }^{\mathrm{a}}$

\begin{tabular}{lll}
\hline Survey question & $\begin{array}{l}\text { Mean rating score }{ }^{\mathrm{b}} \text { (standard } \\
\text { deviation) }\end{array}$ & \multicolumn{1}{c}{ Range } \\
\hline $\begin{array}{l}\text { Overall quality of the education offered in } \\
\text { this session }\end{array}$ & $4.78(0.09)$ \\
Session met stated objectives & $4.67(0.14)$ \\
Session enhanced my current knowledge base & $4.59(0.18)$ \\
Material presented at appropriate level & $4.64(0.13)$ \\
Instructor responsive to participants & $4.72(0.15)$ \\
Material provided useful information for work & $4.65(0.13)$ \\
I am more informed about ACEs and toxic stress, trauma-informed care, and resiliency & $4.60(0.12)$ \\
The case presentation and subsequent discussion increased my ability to better manage the care of & $4.61(0.14)$ \\
my patients & $4.63-4.88)$ \\
Group discussion made a positive impact on my educational experience & $(0.17)$ \\
Questions or concerns were addressed effectively and in a timely manner & $4.68(0.14)$ \\
Zoom platform conducive to learning & $4.59(0.12)$ \\
Effectiveness of didactic speaker & $4.69(0.12)$
\end{tabular}

${ }^{\mathrm{a}}$ Mean number of respondents per survey $(\mathrm{M}=19.5, \mathrm{SD}=6.63$, range: $12-29)$

${ }^{\mathrm{b}} 5$ point Likert scale $1=$ Strongly Disagree, $5=$ Strongly Agree

session components and Zoom platform with all Mean Rating Scores greater than 4.5 (Likert Scale 1= Strongly Disagree, $5=$ Strongly Agree) (Table 3).

Self-reported routine ACE screening within the participants' organizations increased over the course of the series from $26 \%(28 / 106)$ pre-intervention to $45 \%(14 / 31)$ post-intervention. This degree of change did not reach significance. Self-reported importance of ACE screening in community care using a 5-point Likert scale remained high for participants from Baseline $(M=4.69)$ to Final Survey $(\mathrm{M}=4.78)$. A significant number of ECHO participants completed an additional online California ACEs Aware Initiative training curriculum during the course of the series on their own time, reflecting the value of the educational content to participants: $25 \%(26 / 106)$ pre-intervention and $59 \%(19 / 32)$ post-intervention, $\mathrm{X}^{2}(1)=11.47, \mathrm{p}=0.001$ for 
unpaired proportions. McNemar's test determined that the difference between pre-intervention and post-intervention proportions for paired data about completion of additional training was also statistically significant $(p=0.008)$.

In the Final Survey, participants were asked to use a 5-point Likert scale to express "how confident are you in achieving series goals prior to the ECHO and now" for key learning objectives of the series. Paired $t$ test analysis indicated significant change in self-reported confidence across all learning goals pre- and post-intervention (Table 4).

In order to determine likely changes in participant behavior after the training, the Final Survey asked "How will you change your clinical care based on this educational series?" Over $50 \%$ of respondents anticipated each of the following: increased interprofessional communication to promote TIC, improvements in clinic communication to promote care coordination, and changes in treatment approach based on a positive ACE or social determinants of health screen. Participants reported lack of time and staffing to screen for trauma and to provide care coordination as the major barriers to routine trauma screening. Qualitative feedback from participants suggested that the presence of interprofessional collaboration during the sessions, identification of systemslevel barriers and solutions to providing TIC within their communities, and peer support for participants' vicarious trauma were the most valued attributes of the program.

\section{Discussion}

This ECHO training in ACE screening and TIC effectively increased participants' knowledge and confidence to identify ACEs and provide evidence-based TIC within their communities. The virtual workforce development series introduced curricular content created by the California ACEs Aware Initiative and was associated with a significant increase in uptake of an additional key training offered by the ACEs Aware Initiative to its target $\mathrm{MCH}$ workforce.

The curriculum development and delivery processes were simplified by the use of the Project ECHO ${ }^{\circledR}$ model. The adaptable model provided a framework upon which to layer curricular content and promote discussion. Novel features of this ECHO included its focus on TIC in children and the enrollment of professionals from different sectors, including health care, $\mathrm{MCH}$ agencies, behavioral health, and community agencies that serve young children and families. Group leaders encouraged participants to consider TIC solutions at individual, family, and systems levels. The majority of learners rated the Stanford ACEs Aware ECHO sessions to be effective from a learning standpoint. After completing the series, participants across $\mathrm{MCH}$ care sectors self-reported significant increases in confidence to use best-practice skills in their work. Delivered virtually during the COVID-19 pandemic to participants across a wide geographic area, this project supports the efficacy of the ECHO model in training a cross-discipline $\mathrm{MCH}$ workforce to deliver best practice TIC in pediatric populations even during a period of intense stress upon care delivery systems. Importantly, participants found cross-sector collaboration to be a highlight of the series. An unexpected outcome of the project was a qualitative theme of feeling supported by peers in participants' own experiences of work-related vicarious trauma, supporting the importance of building a community of practice.

A challenge of running an ECHO is finding committed partners. Getting busy clinicians and agency representatives to allocate time to attend sessions is difficult. We were able to overcome this challenge through deep professional ties within care communities and word of mouth advertising from key partners. Free CME and CEU credits and strong interest in the curricular topics boosted attendance. Each participant, however, attended only about half of the sessions. Future ECHO projects should consider offering

Table 4 Change in participants' self-reported confidence in achieving series goals prior to participation in ECHO and now

\begin{tabular}{|c|c|c|c|c|c|}
\hline Skill & $\mathrm{n}$ & $\begin{array}{l}\text { Pre-inter- } \\
\text { vention }{ }^{a} \\
\text { "Prior to } \\
\text { Participa- } \\
\text { tion" }\end{array}$ & $\begin{array}{l}\text { Post- } \\
\text { interven- } \\
\text { tion }^{\mathrm{a}} \\
\text { "Now" }\end{array}$ & $\mathrm{t}$ & p value ${ }^{b}$ \\
\hline Define ACEs & 31 & 3.52 & 4.65 & -5.62 & $<0.001 * * *$ \\
\hline Assess a child's ACEs using a PEARLS Screener & 31 & 3.26 & 4.39 & -5.22 & $<0.001 * * *$ \\
\hline Counsel and teach patients to mitigate toxic stress & 31 & 3.26 & 4.39 & -5.48 & $<0.001 * * *$ \\
\hline Prevent vicarious trauma for staff & 31 & 2.90 & 3.90 & -5.98 & $<0.001 * * *$ \\
\hline Cultivate self-compassion as a healthcare or educational professional & 30 & 3.53 & 4.47 & -4.73 & $<0.001 * * *$ \\
\hline Cultivate cultural compassion as a healthcare or educational professional & 31 & 3.42 & 4.26 & -4.99 & $<0.001 * * *$ \\
\hline Identify key elements of organizational trauma-informed systems of care & 31 & 3.03 & 3.94 & -5.33 & $<0.001 * * *$ \\
\hline
\end{tabular}

a-point Likert scale 1 = not at all confident, 2 = only slightly confident, $3=$ somewhat confident, 4 = moderately confident, $5=$ very confident 
monetary stipends to allow organizations to provide protected time for participants to attend.

\section{Limitations}

A limitation of the project was that each participant attended fewer than half of the sessions. Time constraints of participants may limit ECHO education for $\mathrm{MCH}$ professionals. ECHOs require significant time commitments from the lead agency and the participants, and unless this time is built into a participants' work schedule, an ongoing ECHO may not be sustainable for its members. The project was executed in a six month time period. While we met the goals that were created for the group, we found that building trust and a common language across disciplines and care sectors took time. Just as the step-wise curriculum built to discussions about TIC at the organizational level, the series ended.

A limitation of the analysis was that clinician practice change outcomes measures were generated by self-report rather than through chart or billing review. Our data analysis was hindered by the small number of Final Surveys collected, representing fewer than a third of participants in the entire series. We did not conduct a qualitative analysis, which would have expanded upon the anecdotal support for opportunities for cross-sector collaboration and peer-support for participants' vicarious trauma.

\section{Conclusion}

This project not only demonstrated the efficacy of the ECHO model to deliver a curriculum about evidence-based TIC to a virtual community of cross-sector, multi-agency $\mathrm{MCH}$ professionals, but also promoted collaboration and real progress towards creating systems of TIC in communities. Stanford ACEs Aware participants brought a wide range of knowledge and experience, allowing the group to discuss cases from both individual treatment and systems change perspectives. Communication between participants across sectors prompted discovery of both barriers and opportunities to improve TIC in communities. In turn, participants left the sessions knowing that ACEs can be prevented and treated, and armed with best-practice clinical tools to be used when individuals screen positive for ACEs. These tools mitigate negative effects of trauma for individuals and families, elevating screening for ACEs from unnecessary re-traumatization to the first step in identifying and treating trauma and toxic stress. Future directions would allow this enriching cross-sector work to continue over time within a community, with stakeholder families at the table to provide essential community input.
Author Contributions $\mathrm{CB}, \mathrm{BB}$, and LB designed the work; conducted the workforce development project; acquired, analyzed, and/or interpreted data; and made substantial contributions to drafting the manuscript. HF made substantial contributions to design of the work, data analysis, and manuscript preparation. All authors participated in revising the manuscript critically for important intellectual content; and approved of the version to be published. The authors extend their gratitude to Lettie McGuire, EdM, Anne DeBattista PhD, MSN, and Emily Whitgob MD, MEd for their invaluable contributions to this project.

Funding This work was supported by funding from the California Office of the Surgeon General and Department of Healthcare Services' ACEs Aware Initiative Provider Engagement (Network of Care) grant.

Data Availability Data will be made available by request to corresponding author.

Code Availability Data were analyzed using IBM® SPSS ${ }^{\circledR}$ Version 26 software platform.

\section{Declarations}

Conflict of interest The authors declare that they have no conflict of interest.

Ethics Approval Deemed not human subject research by Stanford Institutional Review Board.

Consent to Participate Not required because not human subjects research.

Consent for Publication The authors consent to publication of the data and manuscript.

\section{References}

Allen, D., \& Abresch, C. (2018). Confronting adversity: MCH responds to ACEs. Maternal and Child Health Journal, 22(3), 283-287. https://doi.org/10.1007/s10995-018-2455-8

Arora, S., Kalishman, S. G., Thornton, K. A., Komaromy, M. S., Katzman, J. G., Struminger, B. B., Rayburn, W. F., \& Bradford, A. M. (2017). Project ECHO: A telementoring network model for continuing professional development. Journal of Continuing Education in Health Professions, 37(4), 239-244.

Arora, S., Thornton, K., Murata, G., Deming, P., Kalishman, S., Dion, D., Parish, B., Burke, T., Pak, W., Dunkelberg, J., Kistin, M., Brown, J., Jenkusky, S., Komaromy, M., \& Qualls, C. (2011). Outcomes of treatment for hepatitis $\mathrm{C}$ virus infection by primary care providers. The New England Journal of Medicine, 364(23), 2199-2207. https://doi.org/10.1056/NEJMoa1009370

Bargeman, M., Smith, S., \& Wekerle, C. (2020). Trauma-informed care as a rights-based "standard of care": A critical review. Child Abuse \& Neglect, 119, 104762.

Bellis, M. A., Hughes, K., Ford, K., Ramos Rodriguez, G., Sethi, D., \& Passmore, J. (2019). Life course health consequences and associated annual costs of adverse childhood experiences across Europe and North America: A systematic review and meta-analysis. The Lancet. Public Health, 4(10), e517-e528. https://doi.org/10.1016/ S2468-2667(19)30145-8

Bhusan D., Kotz K., McCall J., Wirtz S., Gilgoff R., Dube S.R., Powers C., Olson-Morgan J., Galeste M., Patterson K., Harris L., Mills A., Bethell C., Burke Harris N., Office of the California Surgeon 
General. (2020). Roadmap for resilience: The California Surgeon General's Report on adverse childhood experiences, toxic stress, and health. Office of the California Surgeon General.

Centers for Disease Control and Prevention. (2019a). Preventing Adverse Childhood Experiences (ACEs): Leveraging the best available evidence. National Center for Injury Prevention and Control, Centers for Disease Control and Prevention. https://www. cdc.gov/violenceprevention/pdf/preventingACES.pdf

Centers for Disease Control and Prevention. (2019b). Press Release: Preventing Adverse Childhood Experiences (ACEs) to improve US Health. https://www.cdc.gov/media/releases/2019/p1105-preventaces.html

Clements, A. D., Haas, B., Cyphers, N. A., Hoots, V., \& Barnet, J. (2020). Creating a communitywide system of trauma-informed care. Progress in Community Health Partnerships: Research, Education, and Action, 14(4), 499-507. https://doi.org/10.1353/ cpr.2020.0055

Dichter, M. E., Teitelman, A., Klusaritz, H., Maurer, D. M., Cronholm, P. F., \& Doubeni, C. A. (2018). Trauma-informed care training in family medicine residency programs results from a CERA survey. Family Medicine, 50(8), 617-622. https://doi.org/10.22454/ FamMed.2018.505481

Doughty, K. (2020). Increasing trauma-informed awareness and practice in higher education. The Journal of Continuing Education in the Health Professions, 40(1), 66-68. https://doi.org/10.1097/ CEH.0000000000000279

Felitti, V. J., Anda, R. F., Nordenberg, D., Williamson, D. F., Spitz, A. M., Edwards, V., Koss, M. P., \& Marks, J. S. (1998). Relationship of childhood abuse and household dysfunction to many of the leading causes of death in adults. The Adverse Childhood Experiences (ACE) Study. American Journal of Preventive Medicine, 14(4), 245-258. https://doi.org/10.1016/s0749-3797(98)00017-8

Forkey, H., Szilagyi, M., Kelly, E. T., Duffee, J., \& Council on foster care, adoption, and kinship care, council on community pediatrics, council on child abuse and neglect, committee on psychosocial aspects of child and family health. (2021). Trauma-informed care. Pediatrics, 148(2), e2021052580. https://doi.org/10.1542/peds. 2021-052580

Green, C., Stein, R. E. K., Storfer-Isser, A., Garner, A. S., Kerker, B. D., Szilagyi, M., Hoagwood, K. E., \& Horwitz, S. M. (2019). Do subspecialists ask about and refer families with psychosocial concerns? A comparison with general pediatricians. Maternal and Child Health Journal, 23(1), 61-71. https://doi.org/10.1007/ s10995-018-2594-y

Horowitz, J. A., \& Cousins, A. (2006). Postpartum depression treatment rates for at-risk women. Nursing Research, 55(2 Suppl), S23-27. https://doi.org/10.1097/00006199-200603001-00005

Horwitz, S. M., Storfer-Isser, A., Kerker, B. D., Szilagyi, M., Garner, A., O’Connor, K. G., Hoagwood, K. E., \& Stein, R. E. K. (2015).
Barriers to the identification and management of psychosocial problems: Changes from 2004 to 2013. Academic Pediatrics, 15(6), 613-620. https://doi.org/10.1016/j.acap.2015.08.006

Hostutler, C. A., Valleru, J., Maciejewski, H. M., Hess, A., Gleeson, S. P., \& Ramtekkar, U. P. (2020). Improving pediatrician's behavioral health competencies through the project ECHO teleconsultation model. Clinical Pediatrics, 59(12), 1049-1057. https://doi. org/10.1177/0009922820927018

Jones, C. M., Merrick, M. T., \& Houry, D. E. (2020). Identifying and preventing adverse childhood experiences: Implications for clinical practice. JAMA, 323(1), 25-26. https://doi.org/10.1001/jama. 2019.18499

Kerns, S. E., Pullmann, M. D., Negrete, A., Uomoto, J. A., Berliner, L., Shogren, D., Silverman, E., \& Putnam, B. (2016). Development and implementation of a child welfare workforce strategy to build a trauma-informed system of support for foster care. Child Maltreatment, 21(2), 135-146. https://doi.org/10.1177/10775 59516633307

Lu, M. C. (2014). Improving maternal and child health across the life course: Where do we go from here? Maternal and Child Health Journal, 18(2), 339-343. https://doi.org/10.1007/ s10995-013-1400-0

Merrick, M. T., Ford, D. C., Ports, K. A., \& Guinn, A. S. (2018). Prevalence of adverse childhood experiences from the 2011-2014 behavioral risk factor surveillance system in 23 states. JAMA Pediatrics, 172(11), 1038-1044. https://doi.org/10.1001/jamapediat rics.2018.2537

Nakamura, Y., Laberge, M., Davis, A., \& Formoso, A. (2019). Barriers and strategies for specialty care access through federally qualified health centers: A scoping review. Journal of Health Care for the Poor and Underserved, 30(3), 910-933. https://doi.org/10.1353/ hpu.2019.0064

Palfrey, N., Reay, R. E., Aplin, V., Cubis, J. C., McAndrew, V., Riordan, D. M., \& Raphael, B. (2019). Achieving service change through the implementation of a trauma-informed care training program within a mental health service. Community Mental Health Journal, 55(3), 467-475. https://doi.org/10.1007/s10597-018-0272-6

Sharif, N., Karasavva, V., Thai, H., \& Farrell, S. (2021). "We're working in a trauma avoidant culture": A qualitative study exploring assertive community treatment providers' perspectives on working with trauma and PTSD in people with severe mental illness. Community Mental Health Journal. https://doi.org/10.1007/ s10597-020-00764-8

Publisher's Note Springer Nature remains neutral with regard to jurisdictional claims in published maps and institutional affiliations. 